\title{
BMJ Open Outcome and comparator choice in molar incisor hypomineralisation (MIH) intervention studies: a systematic review and social network analysis
}

To cite: Elhennawy K, Krois J, Jost-Brinkmann P-G, et al. Outcome and comparator choice in molar incisor hypomineralisation $(\mathrm{MIH})$ intervention studies: a systematic review and social network analysis. BMJ Open 2019;9:e028352. doi:10.1136/ bmjopen-2018-028352

- Prepublication history and additional material for this paper are available online. To view these files, please visit the journal online (http://dx.doi. org/10.1136/bmjopen-2018028352).

Received 08 December 2018 Revised 01 July 2019 Accepted 04 July 2019

Check for updates

(C) Author(s) (or their employer(s)) 2019. Re-use permitted under CC BY-NC. No commercial re-use. See rights and permissions. Published by BMJ.

${ }^{1}$ Department of Orthodontics, Dentofacial Orthopedics and Pedodontics, Charité Universitätsmedizin Berlin, Berlin, Germany

${ }^{2}$ Department of Operative and Preventive Dentistry, Charité - Universitätsmedizin Berlin, Berlin, Germany

Correspondence to

Dr Karim Elhennawy;

karim.elhennawy@charite.de

\section{ABSTRACT}

Objectives Outcome and comparator choice strongly determine the validity and implementation of clinical trial results. We aimed to assess outcome and comparator choice in intervention studies on molar incisor hypomineralisation $(\mathrm{MIH})$ using systematic review and social network analysis (SNA).

Design and data sources Medline, Embase, Cochrane Central, Google Scholar, opengrey.eu as well as DRKS.de and Clinicaltrials.gov were searched for MIH intervention studies. The search covered the period from 1980 to 2019

Eligibility criteria Clinical single-arm/multiarm, controlled/uncontrolled studies reporting on the management of MIH were included. Reported outcomes and comparators were extracted and categorised. SNA was used to evaluate comparator choice and the resulting trial networks.

Data extraction of the 7979 identified records, 100 were evaluated in full text and 35 studies (17 randomised controlled trials, 14 prospective and 4 retrospective cohort studies) were included.

Results In total, 2124 patients with a mean age of 11 years ( $\mathrm{min} / \mathrm{max}$ 6/70 years) were included. Outcomes fell in one of 11 different outcome categories: restoration success, aesthetic improvement, pain/hypersensitivity/ discomfort, mineral gain, space management, anaesthesia effectiveness, preventive success, efficiency, quality of life, gingival and periodontal health and patient satisfaction Comparators were mainly restorative interventions (17 studies), remineralisation (3), treatment of hypersensitivity (10), aesthetic interventions (5) and orthodontic interventions (3). Two highly clustered comparator networks emerged; many interventions were not robustly linked to these networks.

Conclusions MIH intervention studies recorded both clinically centred and patient-centred outcomes. Core outcome set development should consider these and supplement them with outcomes on, for example, applicability. The high number of compared interventions tested in only few studies and our SNA results implicate that the current evidence may not be robust.

\section{INTRODUCTION}

There is increasing interest in the internal and external validity of clinical studies, as
Strengths and limitations of this study

- Molar incisor hypomineralisation $(\mathrm{MIH})$ is a frequent condition. No core outcome set on MIH exists.

- Outcomes and comparators for MIH studies were assessed using a systematic review.

- A network analysis was performed to evaluate the robustness of comparisons.

- The findings of this study will aid in core outcomes definition.

- The available body of evidence is limited and likely not robust.

indicated, for example, by their risk of bias ${ }^{12}$ or their reporting quality. ${ }^{3}$ Two aspects that only recently came into the focus, but have an impact on the validity are (1) outcome and (2) comparator choice.

So far, most clinical researchers chose the outcomes based on their understanding of what was relevant or not; the involvement of further stakeholders into outcome choice was seldom considered. This impacts on the relevance of study findings and may limit their applicability. Also, researchers usually collected a range of outcomes, without necessarily reporting all of them later on (selective reporting); mainly as data on outcomes with unwanted findings (which may nevertheless be relevant) can be omitted. The chosen outcomes and outcome measures may further suffer from limited comparability across studies, decreasing the chance to make the best use of clinical studies by synthesising them. Outcome choice is thus relevant for study validity, applicability and relevance, and implementation into practice. ${ }^{4-6}$

Comparator choice impacts on the overall usefulness and validity of evidence. ${ }^{7}$ Again, usually, most clinical researchers choose the comparators themselves, without necessarily consulting patients or further stakeholders 


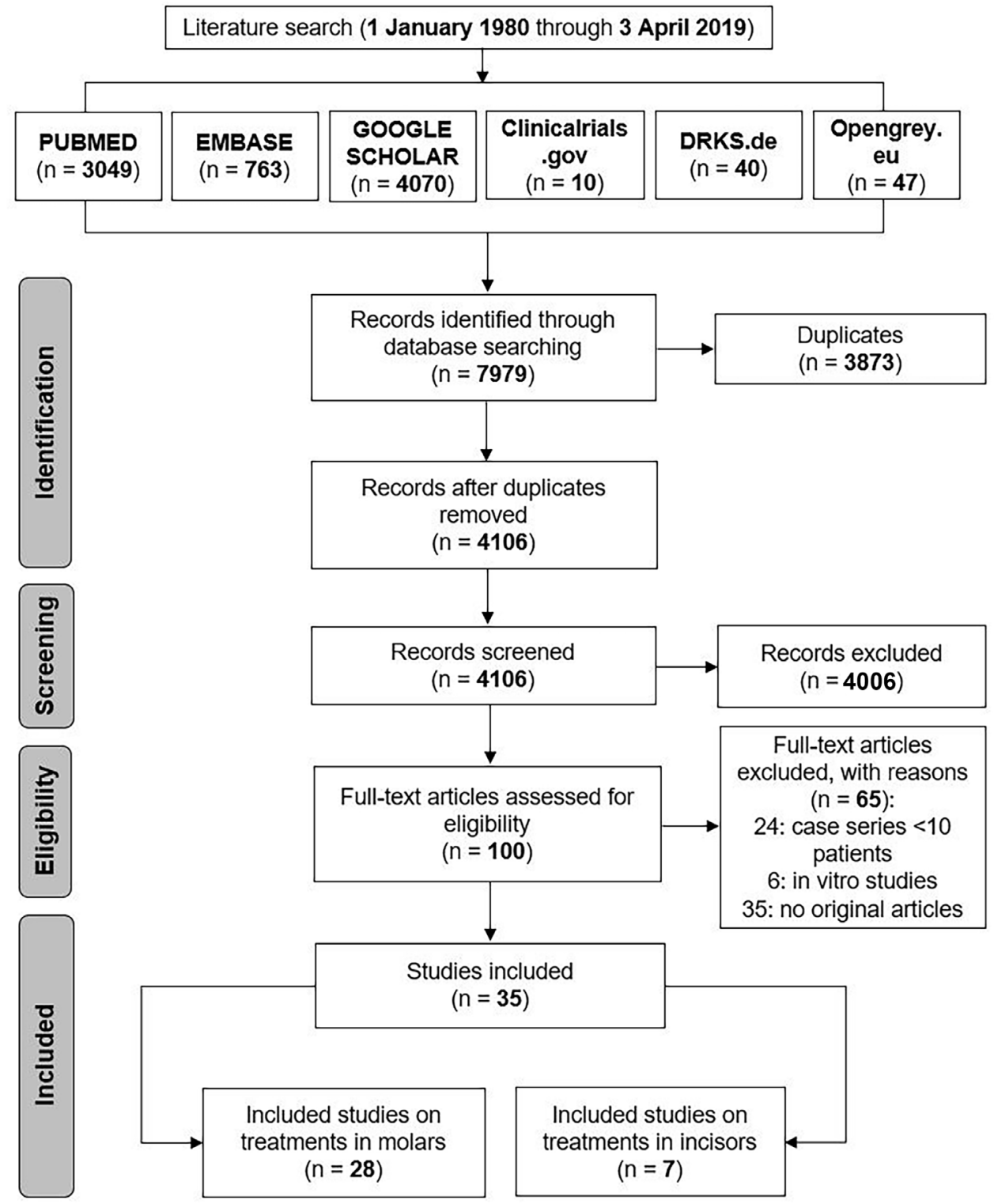

Figure 1 Flow chart of the search.

such as insurers, regulators, etc. Comparators relevant to patients, for example, may hence not be evaluated, while other comparators may be overproportionally employed. $^{8-10}$ The resulting gaps in the evidence may mean important data on possibly useful comparators are unavailable. Also, comparisons against placebo or no intervention (in single-arm studies) or less effective options (so-called straw men) can lead to overestimation of effectiveness. ${ }^{9-11}$ Repeated chain-linked comparisons against less-than-optimal standards were found to significantly distort the totality of evidence. ${ }^{9-11}$ Comparator choice is relevant to make clinical research in a specific field useable, applicable and informative.

The present study assessed outcome and comparator choice in intervention studies on molar incisor hypomineralisation (MIH), a highly prevalent dental developmental disorder with a significant burden for patients and high treatment needs. ${ }^{12}$ MIH is characterised by demarcated creamy-white, yellowish-brown or brown lesions with or without posteruptive enamel breakdown and hypersensitivity, affecting the permanent molars with or without additional affection of the incisors. ${ }^{13-15}$ The severity of the lesions, the symptomatology of the affected tooth as well as the patient's dental age, caries risk and expectations need to be considered in the management of MIH. ${ }^{15}$ Dentists often need to employ different treatment strategies when dealing with MIH patients, including restoring cavities, alleviating pain or improving aesthetics. ${ }^{16}{ }^{17}$ Given the broad spectrum of clinical presentations, individual needs and available treatment modalities, managing MIH is challenging for most practitioners. ${ }^{13-15}$

Assessing the outcome and comparator choice in MIH intervention studies seems warranted. Such an assessment is further useful to inform the development of a core outcome set (COS) for MIH management and prevention studies. COS are a minimum set of outcomes that have been agreed in a systematic consensus process by a diverse group of stakeholders (patients, dentists, 
$\overline{0}$
$\overline{8}$
0

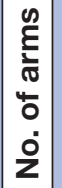

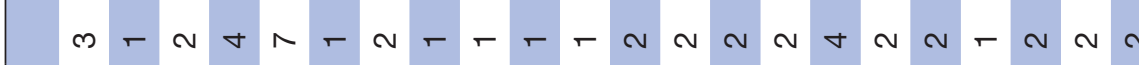

$-e^{2} n+4$

$\sim$

$\frac{8}{\frac{8}{\pi}}$

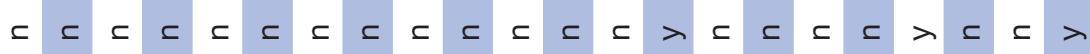

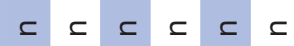

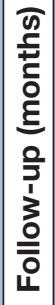

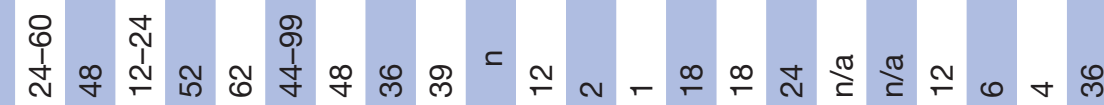

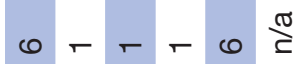

6

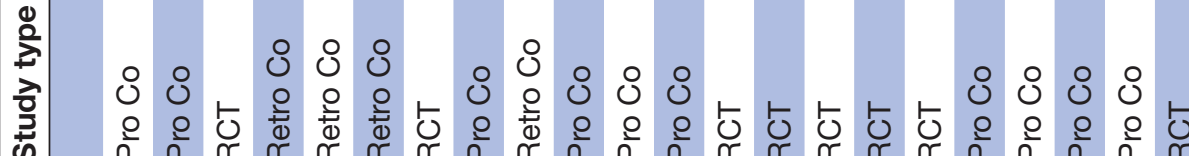

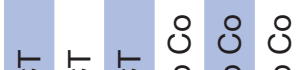

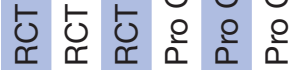

Ł্ণ

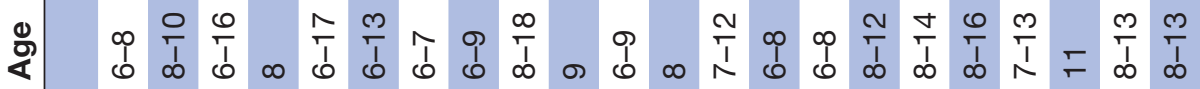

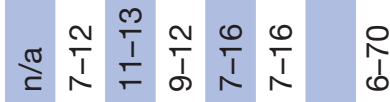

$\frac{\hbar}{\pi}$
$\frac{2}{0}$
$z$

ํำำำ

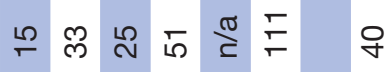

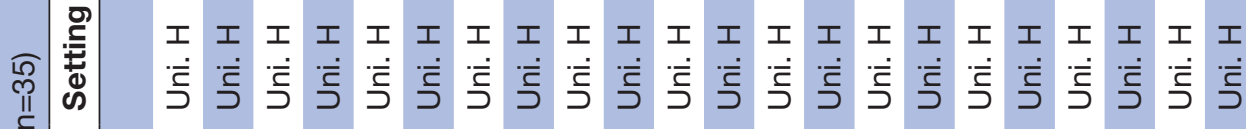

エ エ エ エ エ エ エ

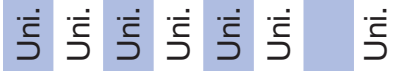

电

ㅇำ

ণิ \&

$\frac{\mathrm{o}}{8}$

g

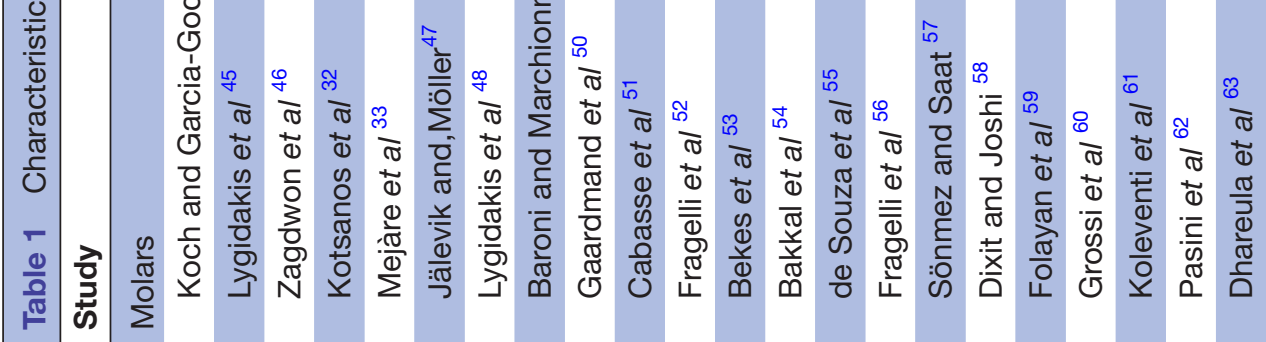

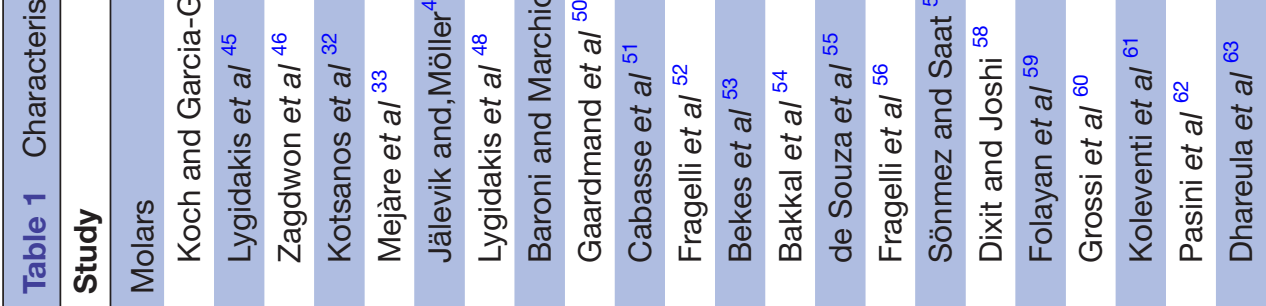

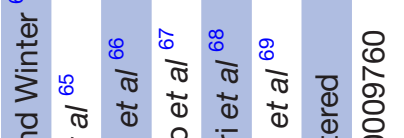

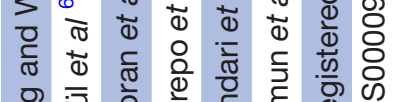

के $\frac{.0}{0}$ $: 0$ क 


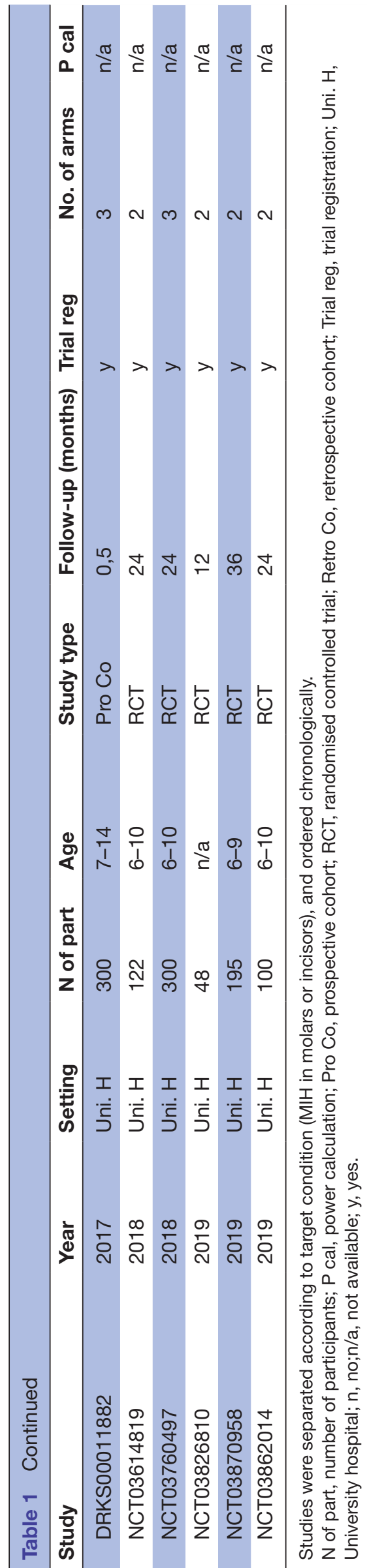

researchers, insurance companies, etc). COS overcome the problem of a possibly limited relevance of chosen outcomes, the risk of selective reporting and the lack of synthesisability of study findings. ${ }^{18}$ A range of COS development initiatives is currently underway in dentistry. ${ }^{19-23}$

We aimed to review the outcomes used in MIH intervention studies to inform the development of a COS on MIH. We further aimed to assess the comparators used in these studies and to analyse the resulting study network. This was done using social network analysis (SNA), a method for evaluating the relationships between factors in a network, ${ }^{8}$ which has been introduced to dentistry recently. ${ }^{24}$ As secondary aim, we evaluated if studies clearly indicated their primary outcome, if studies used a sample size estimation based on this outcome and if studies were registered a priori, as should be expected.

\section{METHODS}

This review was registered on the Core Outcome Measures in Effectiveness Trials initiative website. ${ }^{1}$ In parts, it builds on a previously published review on MIH management. ${ }^{25}$

\section{Search strategy}

The following search was adapted for each database:

(treatment OR management OR prevention) AND (molar incisor hypomineralisation OR molar incisor hypomineralization OR mih).

Searches were developed and run individually for Medline, Embase, Cochrane Central, Google Scholar, opengrey.eu as well as DRKS and Clinicaltrials.gov and cross references were performed without any language restrictions (online supplementary appendix 1). The search covered the period from 1 January 1980 to 3 April 2019 (figure 1).

\section{Data collection}

Inclusion criteria: we included all types of clinical studies (retrospective or prospective, controlled trials or cohort studies) in patients diagnosed with MIH. Note that studies conducted before 2001 on the condition will not have employed the term 'MIH', and may have been missed by our search. This, however, was accepted, as without a clear case definition, other conditions may have been captured by these studies too, without being able to separate conditions post hoc. Studies reported on prevention and/or management interventions for MIH teeth. There were no restrictions on setting, time of follow-up or patients' age. Case reports or case series with a sample size of $<10$ participants were excluded. No language restriction was set; studies in languages other than English, German or Arabic (if present) were translated by native speakers.

Selection process: two authors (FS, KE) screened titles independently and compared their findings. In case of disagreement, titles were included to obtain full texts. Full texts were assessed independently after de-duplication. In cases of disagreement, studies were included after consensus was reached through discussion. 


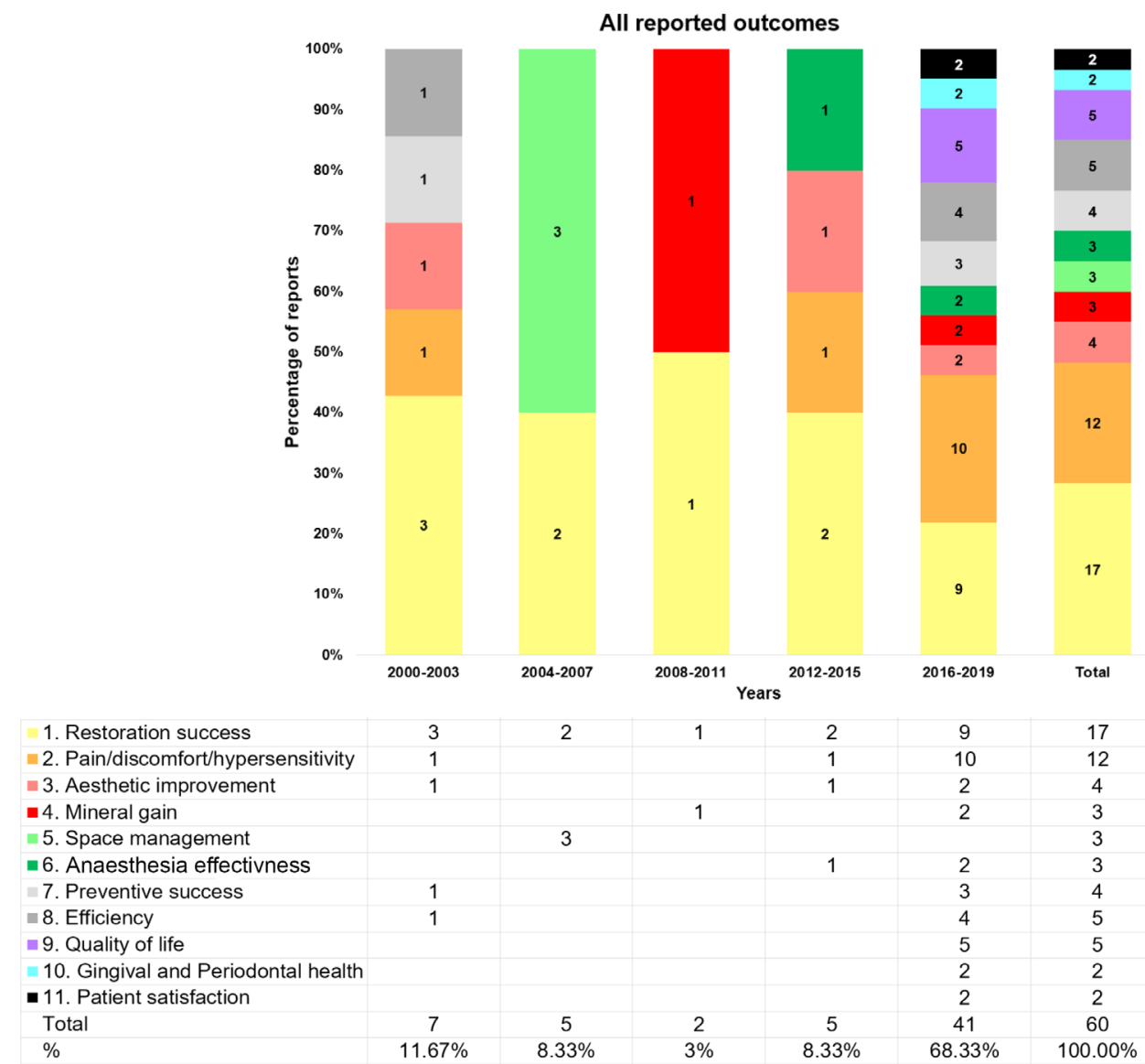

Figure 2 Reported outcomes for molar incisor hypomineralisation intervention studies over time. N number of studies using this outcome in a specific period.

Data extraction: the following data were extracted duplicatively and independently by two authors (KE and FS) following calibration using a pilot database:

- Study details (author name, title, journal, year of publication);

- Study characteristics:

- Study setting (primary or secondary care);

- Number and age of participants;

- Study type (controlled or uncontrolled, prospective or retrospective);

- Target condition (MIH lesions on molars, incisors or both);

- Number of study arms;

- Interventions compared;

- Follow-up period;

- Outcomes assessed, separated for primary and secondary outcome(s). An outcome was considered a primary outcome if it was stated as such, or where the report clearly focused on one outcome. If no primary outcome was identifiable or multiple outcomes were reported, these were considered secondary outcomes;

- Outcome measures.

- Sample size estimation (yes/no);

- Trial registration (yes/no).

\section{Data synthesis}

A list of outcomes was compiled and outcomes with different verbatim terms but similar meanings gathered using a single agreed term. Outcomes were grouped within outcome categories; these were refined through group discussion before all outcomes were categorised using the final agreed terms. The final list of outcome categories comprised 11 items: restoration success, aesthetic improvement, pain and hypersensitivity management, mineral gain, space management, anaesthesia effectiveness, preventive success, efficiency, quality of life, gingival and periodontal health and patient satisfaction. The use of different outcome categories was analysed via descriptive statistics. Exemplary outcomes and outcome measures were allocated to one of these outcome categories by discussion and agreement of two authors (KE and FS). Where there was disagreement, a consensus was achieved through discussion with all authors.

A list of comparators was compiled and comparators were grouped into agreed categories. The granularity of these categories allowed to capture specific comparators (like 'glass ionomer cement restoration') while grouping similar comparators in the same category (eg, different cement brands). Comparator choice was analysed via SNA. In SNA, nodes (termed 'vertices') are formed by comparators and are connected by edges (comparisons made within 
Table 2 Reported outcome category, outcome examples and outcomes measures, ordered according to the frequency of use in included studies

\begin{tabular}{|c|c|c|}
\hline Outcome category & Outcome examples & Exemplary outcome measures \\
\hline $\begin{array}{l}\text { Pain/discomfort/ } \\
\text { hypersensitivity }\end{array}$ & $\begin{array}{l}\text { Response to stimulus } \\
\text { Pain during and after dental treatment/ } \\
\text { intervention }\end{array}$ & $\begin{array}{l}\text { Schiff Cold Air Sensitivity Scale } \\
\text { Questionnaires } \\
\text { Modified behaviour pain scale } \\
\text { Visual Analogue Scale (VAS) }\end{array}$ \\
\hline Aesthetic improvement & Aesthetic improvement & $\begin{array}{l}\text { Questionnaires } \\
\text { Clinical photography }\end{array}$ \\
\hline Mineral gain & Mineral gain & $\begin{array}{l}\text { Laser fluorescence readings } \\
\text { Scanning electron microscope/energy dispersive X-ray } \\
\text { spectrometry } \\
\text { Quantitative light-induced fluorescence }\end{array}$ \\
\hline Anaesthesia effectiveness & $\begin{array}{l}\text { Anaesthesia technique } \\
\text { Need for local anaesthesia }\end{array}$ & $\begin{array}{l}\text { Presence of pain during treatment } \\
\text { Pain efficacy scale }\end{array}$ \\
\hline Preventive success & $\begin{array}{l}\text { Clinical performance } \\
\text { Sealant quality } \\
\text { Ability to prevent caries and enamel } \\
\text { breakdown }\end{array}$ & Success/Modified USPHS criteria \\
\hline Efficiency & Costs of treatment & $\begin{array}{l}\text { Placement time } \\
\text { Used materials } \\
\text { Laboratory costs }\end{array}$ \\
\hline Quality of life & Oral health-related quality of life (OHRQoL) & $\begin{array}{l}\text { Self-administered OHRQoL questionnaires child oral } \\
\text { health impact profile (COHIP G-19), child perceptions } \\
\text { questionnaire (CPQ 8-10), (CPQ 11-14) }\end{array}$ \\
\hline
\end{tabular}

the same trial). In a graphical analysis, the node diameter represents the number of comparator arms forming the node and thickness of edges represents the number of direct comparisons. We performed separate analyses (and graphic representations) for studies on MIH in molars versus incisors. Statistical analysis included the assessment of the degree (average number of comparators per node) and the clustering coefficient (values of 1 indicate that all possible connections were made, while values of 0 indicate that only the minimum number of connections were made). ${ }^{26-28}$ Statistical analysis was only performed for the main network in each subanalysis (molars; incisors). The Python package NetworkX was used.

\section{Patient and public involvement}

Patients were not involved in this study at this point but will be during the core outcomes definition.

\section{RESULTS}

\section{Included studies}

The database search yielded 7979 records; 4106 remained after de-duplication. There were 100 potentially relevant articles and the full texts of all these 100 articles were located ( $100 \%$ retrieval rate); 35 met the inclusion criteria and were included (figure 1).

\section{Characteristics of included trials}

Of the 35 included studies, all (100\%) were conducted in a secondary care setting (hospital or university). The total number of participants was 2124; per study, a mean of 60 (range 12-300) participants were included. Only children (mean age $<12$ years) were included in 33 included reports $(94 \%)$. Only one $(3 \%)$ study reported on adults (mean age 33 years). In two other publications $(6 \%)$, it was not possible to determine the age of the participants. There were 10 (29\%) one-arm studies, 18 (51\%) two-arm 


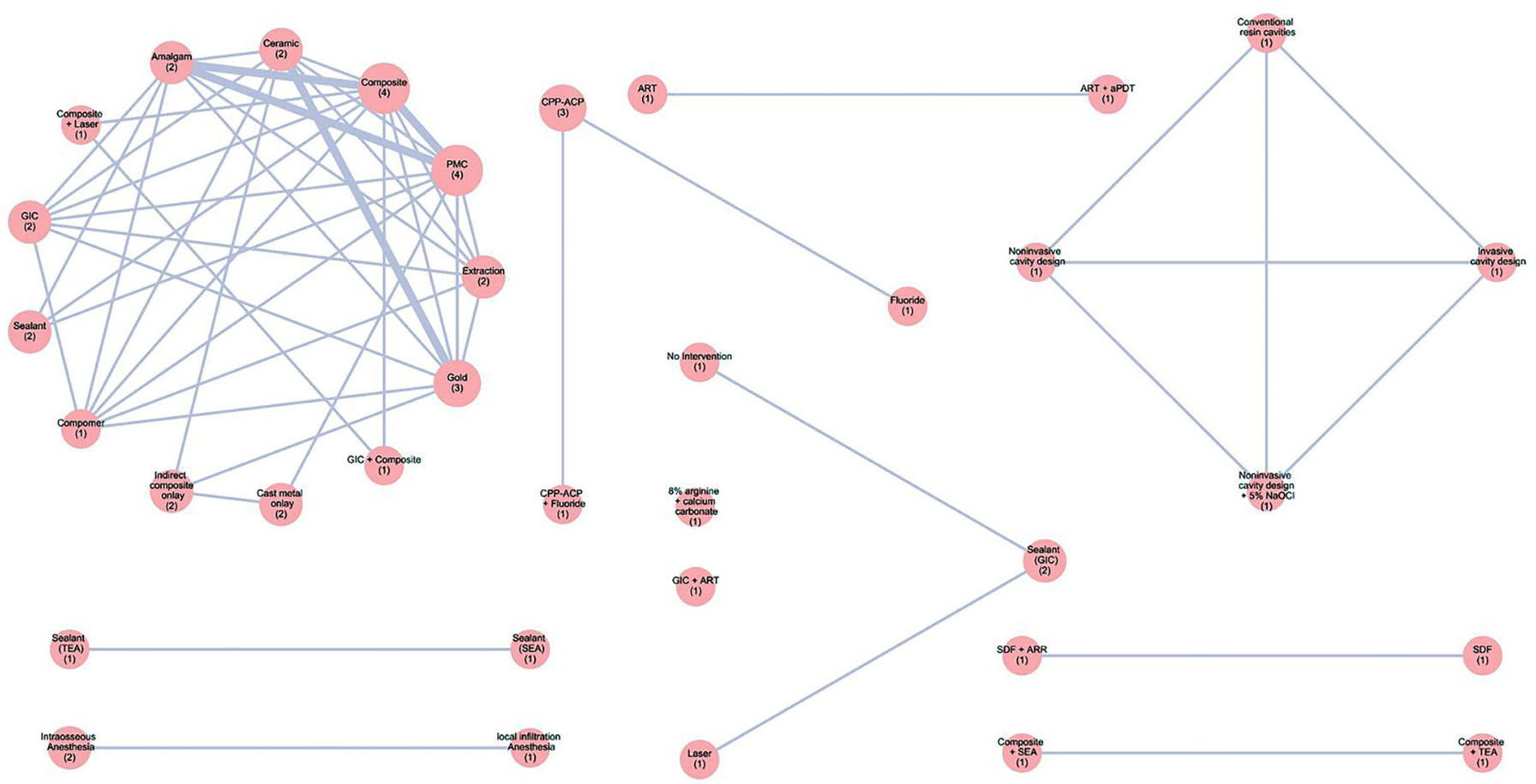

Figure 3 Networks of comparisons made in molars. Different comparators (nodes) were compared directly with each other. The node diameter represents the number of studies involving this comparator. Moreover, the number of studies is added between brackets in each node, the thickness of the edge represents the number of direct comparisons between two comparators. Certain comparators were not connected to the main network. aPDT, low-intensity laser and photodynamic therapy; ART, atraumatic restorative treatment; ARR, atraumatic resin restoration; CPP-ACP, casein phosphopeptide-amorphous calcium phosphate; GIC, glass ionomer cement; $\mathrm{HCl}$, hydrochloric acid; $\mathrm{NaOCl}$, sodium hypochlorite; PMC, preformed metal crowns; SDF, silver diamine fluoride; SEA, self-etching adhesive; TEA, total-etch adhesive.

studies, $3(9 \%)$ three-arm studies and $4(11 \%)$ multiarm studies. Further details on the included studies can be found in table 1 .

\section{Outcome choice}

In total, 11 outcome categories were deduced from the included studies (figure 2, table 2). The most frequent specific categories were 'restoration success' and 'pain/ discomfort/hypersensitivity', with 17 (49\%) and 12 $(34 \%)$ studies reporting them, respectively. The next most common were 'quality of life' and 'efficiency' (each five studies, 14\%); 'aesthetic improvement' and 'preventive success' (four studies, 11\%); 'mineral gain', 'space management' and 'anaesthesia effectiveness' (each three studies, 9\%). The least common ones were 'patient satisfaction' and 'gingival and periodontal health' (each two studies, 6\%). Outcome categories that have increased in use (from 2000-2009 to 2010-2018) included 'aesthetic improvement', 'mineral gain', 'efficiency', and 'gingival and periodontal health'.

\section{Findings for molars}

For molars, 10 outcome categories were identified from the included studies. Those were: 'restoration success' with a total of $17 / 28$ studies reporting on it $(15 / 17$ as primary outcome and 2/17 as secondary outcome); 'pain/ discomfort/hypersensitivity' with a total of 12/28 studies reporting on it (4/12 as primary outcome and $8 / 11$ as secondary outcome); 'quality of life' with a total of $5 / 28$ studies reporting on it (2/5 as primary outcome and $3 / 5$ as secondary outcome); 'efficiency' with a total of $5 / 28$ studies reporting on it ( $1 / 5$ as primary outcome and $4 / 5$ as secondary outcome); 'preventive success' with a total of 4/28 studies reporting on it (3/4 as primary outcome and $1 / 4$ as secondary outcome); 'anaesthesia effectiveness' with a total of $3 / 28$ studies reporting on it $(2 / 3$ as primary outcome and $1 / 3$ as secondary outcome); 'space management' with a total of $3 / 28$ studies reporting on it ( $1 / 3$ as primary outcome and $2 / 3$ as secondary outcome); 'mineral gain' with a total of $2 / 28$ studies reporting on it (all as primary outcome); 'gingival and periodontal health' with a total of $2 / 28$ studies reporting on it $(1 / 2$ as primary outcome and $1 / 2$ as secondary outcome); 'patient satisfaction' with a total of 2/28 studies reporting on it (all as secondary outcome).

\section{Findings for incisors}

For incisors, only four outcome categories were identified from the included studies. Those were: 'aesthetic improvement' with a total of $4 / 7$ studies reporting on it (all as primary outcome); 'pain/discomfort/hypersensitivity' with a total of $1 / 7$ study reporting on it (as primary outcome); 'quality of life' with a total of $1 / 7$ study reporting on it (as primary outcome); 'mineral gain' with a total of $1 / 7$ study reporting on it (as primary outcome). 

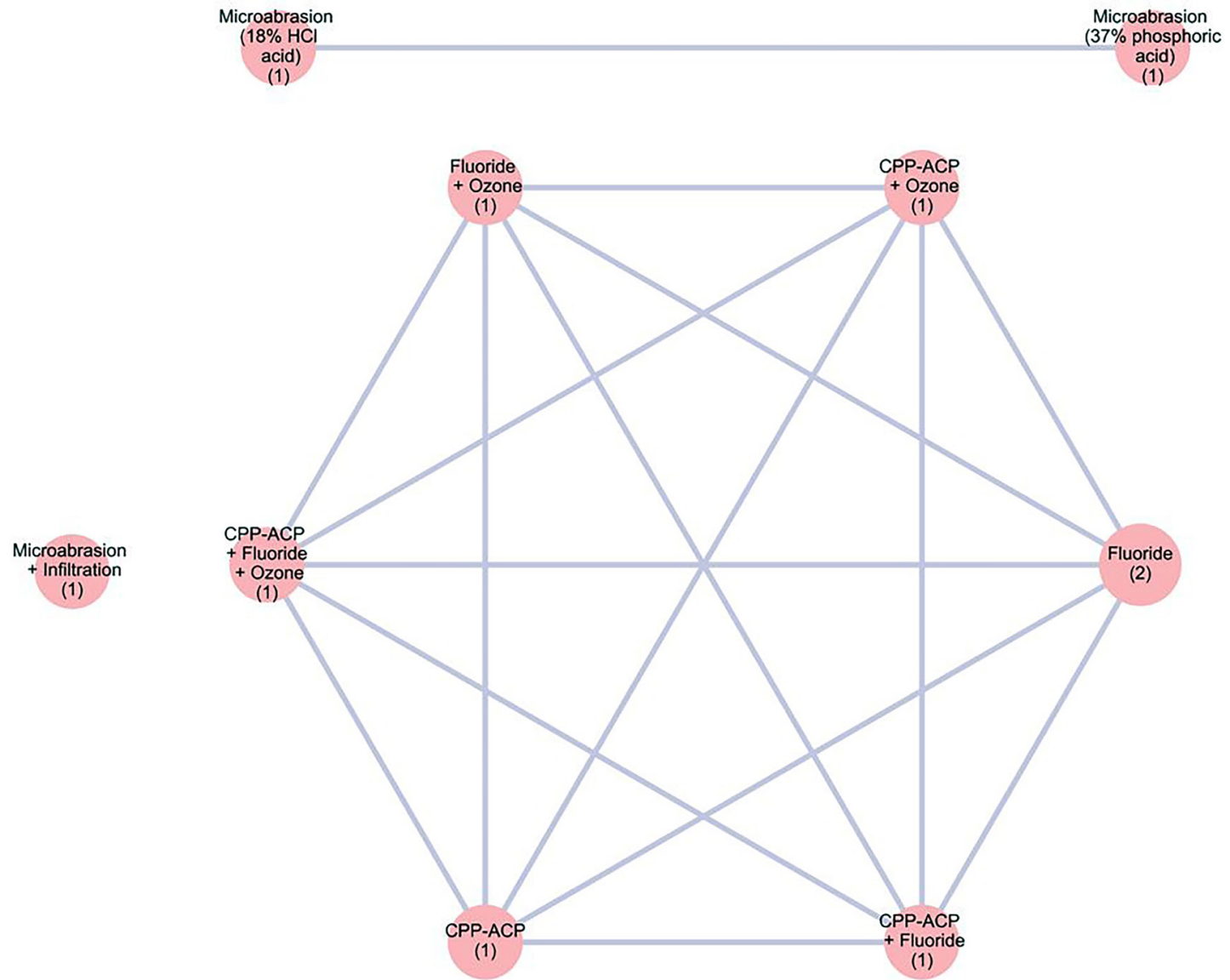

Figure 4 Networks of comparisons made in incisors. Different comparators (nodes) were compared directly with each other. The node diameter represents the number of studies involving this comparator. Moreover, the number of studies is added between brackets in each node, the thickness of the edge the number of direct comparisons between two comparators. Certain comparators were not connected to the main network. CPP-ACP, casein phosphopeptide-amorphous calcium phosphate; $\mathrm{HCl}$, hydrochloric acid.

\section{COMPARATOR CHOICE}

Two separate analyses on comparator choice were performed; one for studies on molars and one on incisors. In both groups, a loosely connected main network and several further, unconnected networks or comparators were present, indicating poor connectivity between comparators (figures 3 and 4). Certain comparators were more frequently chosen than others.

In molars (figure 3), many studies compared different restorative strategies, for example, composite (with different brands also tested against each other), metal, ceramic or cement restorations. Further comparisons, non-connected to this main (restorative) network, involved caries preventive interventions, management of hypersensitivity and cavity preparation and condition techniques. The mean degree of the main, restorative network was 5.9, with a density of 0.49 . The cluster coefficient (which ranges from 0 -no clustering to $1-$ maximum clustering) was 0.76 , indicating that there was significant clustering, with certain comparators being compared with each other (in 'cliques'), while other possible comparisons (against comparators outside of these cliques) not having been made.

In incisors (figure 4), a main network, comparing different remineralisation strategies, emerged, with two further networks and two further, non-connnected comparators on aesthetic management of MIH. The mean degree of the main (remineralisation) network was 5 , with a density of 1.0 . The cluster coefficient was 1.0 , indicating that there were 'cliques' of comparators present, with comparators being mainly compared within and not across these cliques.

\section{Primary outcome and sample size calculation}

Primary outcomes could be identified in all $35(100 \%)$ reports (table 3). Throughout all years (2000 to 2019), 'restoration success' was the most frequently assessed primary outcome $(17 / 35)$. Information on sample size 


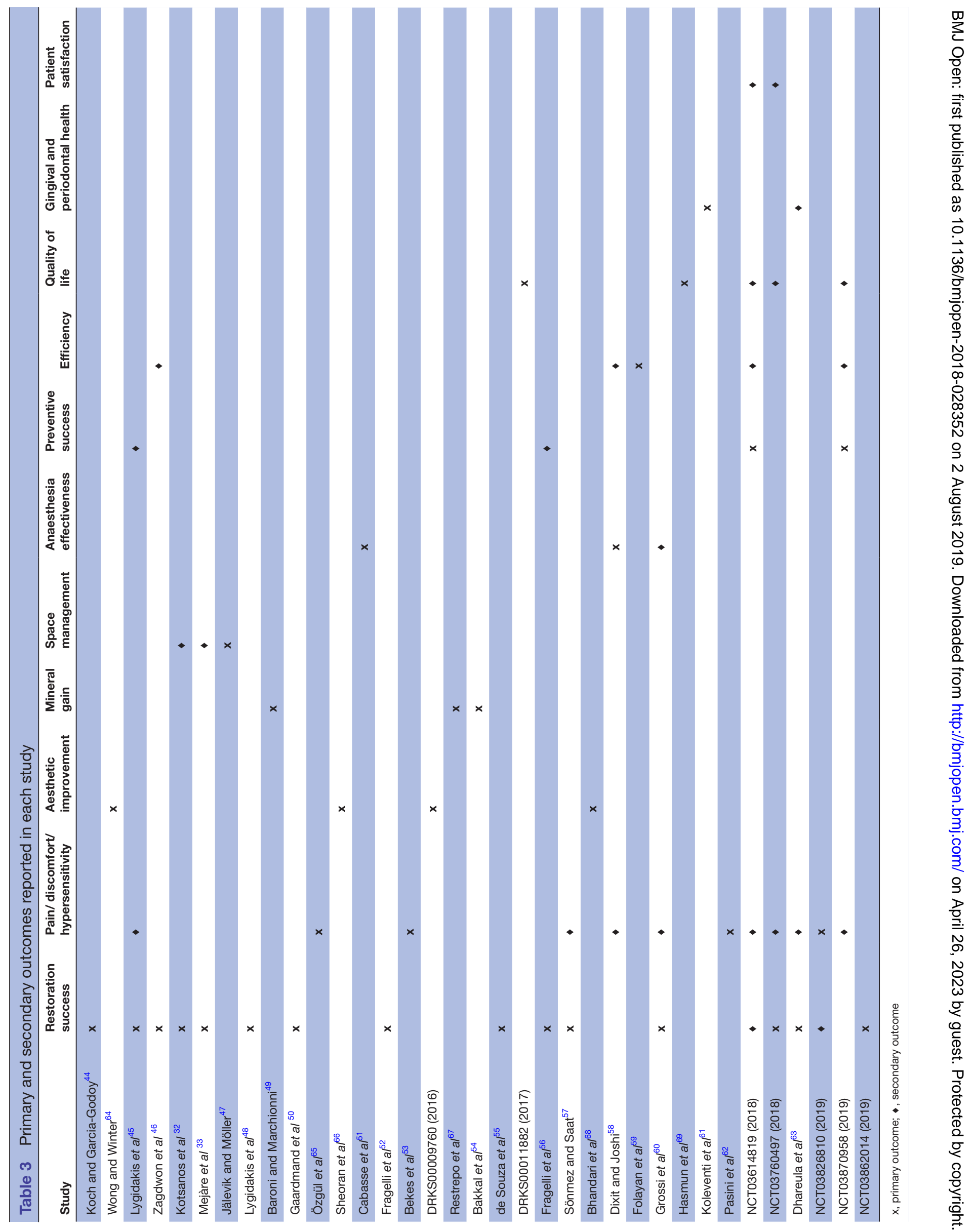


calculation was provided in seven $(20 \%)$ reports, all but one being published between 2016 and 2019. Of these seven reports, five $(71 \%)$ related this calculation to the primary outcome.

\section{Trial registration reporting}

Only $10(29 \%)$ of all articles reported a trial registration. ${ }^{29}$ In the 10 years following the publication of the first Consolidated Standards of Reporting Trials (CONSORT) statement (2001-2010), not a single report included a trial registration. Following the publication of the second CONSORT statement (2011-2019), this increased to $29 \%$.

\section{DISCUSSION}

This systematic review assessed outcome and comparator choice in MIH intervention studies, and their change over time. We found that studies recorded a large range of outcomes, especially when considering the limited number of studies overall, and that the diversity of these outcomes is increasing. This is reassuring, and the findings of this review are helpful to develop a COS. We also found that despite the low number of studies available, a large range of different interventions was tested, which led to the occurrence of segregated networks. Resulting from this clustering and the fact that most interventions were not well compared against alternatives, the current body of evidence on MIH interventions is likely not robust.

The outcomes used in MIH intervention studies focused on two main areas: restoration success (measured via the USPHS criteria or similar tools) and pain/discomfort/hypersensitivity (measured via scales like the Visual Analogue Scale or the Schiff Cold Air Sensitivity Scale). Combined, these two areas accounted for the majority of primary and all reported outcomes. Both restoring $\mathrm{MIH}$ teeth and managing pain can be assumed to be the major difficulties dentists face when treating MIH. Research has shown that MIH-affected children receive and need more dental treatment compared with unaffected children. ${ }^{30-35}$ Also already restored MIH molars remain within short re-treatment cycles. ${ }^{30}$ The porous nature of MIH enamel and the presence of posteruptive enamel breakdown leads to the presence of hypersensitivity and pain, which are often the patients' chief complaints and affect their quality of life. They also increase the risk of dental fear and anxiety. ${ }^{15}$ 36-38 Overall, the focus on how to best restore these teeth and alleviate pain seems justified.

Nevertheless, the use of other outcome categories like quality of life or efficiency appears to be growing, reflecting an ongoing shift to patient-centred care (and research) and the increasing relevance of health economics in today's resource-limited healthcare settings. We will, in the next stage of our COS development, suggest these outcomes to be included in the COS on MIH intervention studies, and will seek stakeholder consensus on their inclusion (or not).
We also investigated further outcome-related aspects in the included studies. For example, trial registration, one of the recommendations of the CONSORT statement, ${ }^{39} 40$ was found in only 10 studies (and even very recent studies did not commonly report on this). While such registration may be seen as a prerogative of controlled trials, also single-arm prospective trials should clearly state what is to be investigated using which methods and tools in what population before commencing the study. This does not seem to be the case. Registration would help to reduce selective outcome reporting and could also assist in improving reporting standards (and general methodology) in MIH intervention studies.

Also, of the 35 reports, only 7 studies reported a sample size calculation, and of these, only 5 related this to the primary outcome. Again, while such calculations are mainly demanded for controlled prospective trials, researchers should have a rational basis for calculating the number of participants needed in any study (regardless of its design), be it to ascertain that differences between the interventions can be detected with a planned level of statistical confidence or be it to reduce statistical noise (allowing somewhat firm conclusions). Sample size calculation is a key recommendation in the CONSORT statement, published in $2001^{40}$ and revised in $2010 .^{39} \mathrm{It}$ was promising to find that, since this revision, more publications reported on a sample size calculation (while the overall number remained low).

Our network analysis found that most comparisons in MIH trials included few, favoured comparators; many possible comparisons were never made, and some comparators were not at all compared against alternatives. Moreover, and understandable, comparators focusing on specific indications (managing pain, restoring cavities, improving aesthetics) were connected within, not between these indications. Overall, the information emerging from such poorly connected networks with regard to the relative efficacy of the interventions (answering the question of which intervention is most suited for a specific therapeutic goal) is likely not robust. The small sample sizes in most studies further add to the limited robustness of the existing evidence. Overall, the relatively 'young' field of MIH research has so far not accrued sufficiently robust data, which allows strong recommendations for clinicians.

This study has a number of limitations. First, the effort to improve COS methodology is ongoing, and our review used only one of several available strategies suggested for COS developers. For example, it seems that to reach saturation on outcomes and outcome categories, it may not be necessary to search multiple databases, ${ }^{41}$ while we did so, also as this review was an update of a previous one and we aimed to apply the same methodology. Second, developing outcome categories and assigning specific verbatim outcomes to these categories is challenging, ${ }^{21}$ often as outcomes are either inter-related or composites, capturing different outcome categories. ${ }^{42}$ While there is no acknowledged MIH outcome classification system, it 
is clear that alternative classifications may have resulted in changes to the granularity and focus of the results. Third, researchers tend to publish multiple reports from the same clinical trial. ${ }^{43}$ This can be necessary to report on the dataset at different time points or to report on multiple analyses. Data are then divided and spread across multiple publications, which makes linking or summarising these articles very difficult. We assume to have captured all articles given that the field is limited. Last, in order to limit selective outcome bias and in the attempt of including the most recent trials, registries were searched in our study, too. This, however, has its limitations, since there are often incomplete or unclear registrations, and we were only limitedly able to extract data.

\section{CONCLUSIONS}

Outcomes reported in interventional trials for the management and prevention of MIH focused on the performance of restorative materials or and the management of pain and hypersensitivity associated with MIH-affected teeth. Outcomes related to oral-health related quality of life and economics have grown in use and are likely to be important in the future. Patient-reported or patient-centred outcomes were rarely reported. COS development should include these and may supplement them with new outcomes, for example, on applicability. The high number of compared interventions tested in only a few studies and our SNA results implicate that current evidence may not be robust.

\section{Trial status (registration)}

COMET initiative online http://www.comet-initiative. org/studies/details $/ 1155^{1}$

Acknowledgements We acknowledge support from the German Research Foundation (DFG) and the OpenAccess Publication Funds of Charité Universitätsmedizin Berlin.

Contributors The study was conceived by KE and FS. KE, FS and JK analysed, interpreted the data.KE, P-GJ-B and FS wrote the manuscript. All authors read and approved the manuscript.

Funding The authors have not declared a specific grant for this research from any funding agency in the public, commercial or not-for-profit sectors.

Competing interests None declared.

Patient consent for publication Not required.

Provenance and peer review Not commissioned; externally peer reviewed.

Data availability statement All data relevant to the study are included in the article or uploaded as supplementary information.

Open access This is an open access article distributed in accordance with the Creative Commons Attribution Non Commercial (CC BY-NC 4.0) license, which permits others to distribute, remix, adapt, build upon this work non-commercially, and license their derivative works on different terms, provided the original work is properly cited, appropriate credit is given, any changes made indicated, and the use is non-commercial. See: http://creativecommons.org/licenses/by-nc/4.0/.

\section{REFERENCES}

1. COMET. comet - initiative. org [Accessed 23 Jan 2017].

2. Higgins JPT, Altman DG, Gøtzsche PC, et al. The Cochrane collaboration's tool for assessing risk of bias in randomised trials. BMJ 2011;343:d5928.
3. Schulz KF, Altman DG, Moher D, et al. Consort 2010 statement: updated guidelines for reporting parallel group randomised trials. BMC Med 2010;8:18.

4. Prinsen CAC, Vohra S, Rose MR, et al. Core Outcome Measures in Effectiveness Trials (COMET) initiative: protocol for an international Delphi study to achieve consensus on how to select outcome measurement instruments for outcomes included in a 'core outcome set'. Trials 2014;15:247.

5. Chiarotto A, Ostelo RW, Turk DC, et al. Core outcome sets for research and clinical practice. Braz J Phys Ther 2017;21:77-84.

6. Levey C, Innes N, Schwendicke F, et al. Outcomes in randomised controlled trials in prevention and management of carious lesions: a systematic review. Trials 2017;18:515.

7. Ioannidis JPA, Greenland S, Hlatky MA, et al. Increasing value and reducing waste in research design, conduct, and analysis. The Lancet 2014;383:166-75.

8. Rizos EC, Salanti G, Kontoyiannis DP, et al. Homophily and cooccurrence patterns shape randomized trials agendas: illustration in antifungal agents. J Clin Epidemiol 2011;64:830-42.

9. Salanti G, Higgins JPT, Ades AE, et al. Evaluation of networks of randomized trials. Stat Methods Med Res 2008;17:279-301.

10. Salanti G, Kavvoura FK, loannidis JPA. Exploring the geometry of treatment networks. Ann Intern Med 2008;148:544-53.

11. Salanti G. Indirect and mixed-treatment comparison, network, or multiple-treatments meta-analysis: many names, many benefits, many concerns for the next generation evidence synthesis tool. Res Synth Methods 2012;3:80-97.

12. Schwendicke F, Elhennawy K, Reda S, et al. Global burden of molar incisor hypomineralization. J Dent 2018;68:10-18.

13. Weerheijm KL, Duggal M, Mejàre I, et al. Judgement criteria for molar incisor hypomineralisation $(\mathrm{miH})$ in epidemiologic studies: a summary of the European meeting on miH held in Athens, 2003. Eur J Paediatr Dent 2003;4:110-3.

14. Weerheijm KL. Molar incisor hypomineralization $(\mathrm{miH})$ : clinical presentation, aetiology and management. Dent Update 2004;31:9-12.

15. Lygidakis NA, Wong F, Jälevik B, et al. Best clinical practice guidance for clinicians dealing with children presenting with Molar-IncisorHypomineralisation (miH): an EAPD policy document. Eur Arch Paediatr Dent 2010;11:75-81.

16. Neves AB, Americano GCA, Soares DV, et al. Breakdown of demarcated opacities related to molar-incisor hypomineralization: a longitudinal study. Clin Oral Investig 2019;23:611-5.

17. Steffen R, Krämer N, Bekes K. The Würzburg MIH concept: the MIH treatment need index (MIH TNI): a new index to assess and plan treatment in patients with molar incisior hypomineralisation (MIH). Eur Arch Paediatr Dent 2017;18:355-61.

18. Tugwell $P$, Boers M, Brooks $P$, et al. OMERACT: an international initiative to improve outcome measurement in rheumatology. Trials 2007;8:38.

19. Innes NPT, Schwendicke F, Lamont T. How do we create, and improve, the evidence base? Br Dent J 2016;220:651-5.

20. Lamont T, Schwendicke F, Innes N. Why we need a core outcome set for trials of interventions for prevention and management of caries. Evid Based Dent 2015;16:66-8.

21. Fleming PS, Koletsi D, O'Brien K, et al. Are dental researchers asking patient-important questions? A scoping review. J Dent 2016;49:9-13.

22. Hancocks S. Asking the right questions. Br Dent J 2016;221:47.

23. Smaïl-Faugeron V, Fron Chabouis H, Durieux P, et al. Development of a core set of outcomes for randomized controlled trials with multiple outcomes - example of pulp treatments of primary teeth for extensive decay in children. PLoS One 2013;8:e51908.

24. Schwendicke F, Blunck U, Paris S, et al. Choice of comparator in restorative trials: a network analysis. Dental Materials 2015;31:1502-9.

25. Elhennawy K, Schwendicke F. Managing molar-incisor hypomineralization: a systematic review. J Dent 2016;55:16-24.

26. Jackson M. Social and economic networks. Princeton: Princeton University Press, 2008.

27. Mahony H, Tsalatsanis A, Kumar A, et al. Evolution of treatment regimens in multiple myeloma: a social network analysis. PLoS One 2014;9:e104555

28. Valente T. Social networks and health: models, methods, and applications. New York: Oxford University Press, 2010.

29. Schulz KF, Altman DG, Moher D, et al. Consort 2010 statement: updated guidelines for reporting parallel group randomized trials. Open Med 2010;4:e60-8.

30. Leppäniemi A, Lukinmaa PL, Alaluusua S. Nonfluoride hypomineralizations in the permanent first molars and their impact on the treatment need. Caries Res 2001;35:36-40. 
31. Jälevik B, Klingberg GA, treatment D. Dental treatment, dental fear and behaviour management problems in children with severe enamel hypomineralization of their permanent first molars. Int $J$ Paediatr Dent 2002:12:24-32.

32. Kotsanos N, Kaklamanos EG, Arapostathis K. Treatment management of first permanent molars in children with Molar-Incisor Hypomineralisation. Eur J Paediatr Dent 2005;6:179-84.

33. Mejàre I, Bergman E, Grindefjord M. Hypomineralized molars and incisors of unknown origin: treatment outcome at age 18 years. Int $J$ Paediatr Dent 2005:15:20-8.

34. Chawla N, Messer LB, Silva M. Clinical studies on molar-incisorhypomineralisation Part 1: distribution and putative associations. Eur Arch Paediatr Dent 2008;9:180-90.

35. Jälevik B, Klingberg G. Treatment outcomes and dental anxiety in 18-year-olds with $\mathrm{MIH}$, comparisons with healthy controls - a longitudinal study. Int J Paediatr Dent 2012;22:85-91.

36. Weerheijm KL, Jälevik B, Alaluusua S. Molar-Incisor Hypomineralisation. Caries Res 2001;35:390-1. 47479.

37. Rodd HD, Morgan CR, Day PF, et al. Pulpal expression of TRPV1 in molar incisor hypomineralisation. Eur Arch Paediatr Dent 2007:8:184-8.

38. Fagrell TG, Lingström P, Olsson $S$, et al. Bacterial invasion of dentinal tubules beneath apparently intact but hypomineralized enamel in molar teeth with molar incisor hypomineralization. Int $J$ Paediatr Dent 2008;18:333-40.

39. Moher D, Hopewell S, Schulz KF, et al. Consort 2010 explanation and elaboration: updated guidelines for reporting parallel group randomised trials. BMJ 2010;340:c869.

40. Moher D, Schulz KF, Altman DG. The CONSORT statement: revised recommendations for improving the quality of reports of parallelgroup randomised trials. The Lancet 2001;357:1191-4.

41. Gargon E, Williamson PR, Clarke M. Collating the knowledge base for core outcome set development: developing and appraising the search strategy for a systematic review. BMC Med Res Methodol 2015; $15: 26$

42. Echevarria C, Sinha IP. Heterogeneity in the measurement and reporting of outcomes in studies of electronic cigarette use in adolescents: a systematic analysis of observational studies. Tob Control 2017;26:247-253.

43. Ebrahim S, Montoya L, Kamal el Din M, et al. Randomized trials are frequently fragmented in multiple secondary publications. $J$ Clin Epidemiol 2016;79:130-9.

44. Koch MJ, García-Godoy F. The clinical performance of laboratoryfabricated Crowns placed on first permanent molars with developmental defects. J Am Dent Assoc 2000;131:1285-90.

45. Lygidakis NA, Chaliasou A, Siounas G. Evaluation of composite restorations in hypomineralised permanent molars: a four year clinical study. Eur J Paediatr Dent 2003;4:143-8.

46. Zagdwon AM, Fayle SA, Pollard MA. A prospective clinical trial comparing preformed metal Crowns and cast restorations for defective first permanent molars. Eur J Paediatr Dent 2003;4:138-42.

47. Jälevik B, Möller M. Evaluation of spontaneous space closure and development of permanent dentition after extraction of hypomineralized permanent first molars. Int $J$ Paediatr Dent 2007; 17:328-35.

48. Lygidakis NA, Dimou G, Stamataki E. Retention of fissure sealants using two different methods of application in teeth with hypomineralised molars $(\mathrm{miH})$ : a 4 year clinical study. Eur Arch Paediatr Dent 2009;10:223-6.

49. Baroni $\mathrm{C}$, Marchionni S. Mih supplementation strategies: prospective clinical and laboratory trial. J Dent Res 2011;90:371-6.

50. Gaardmand E, Poulsen S, Haubek D. Pilot study of minimally invasive cast adhesive copings for early restoration of hypomineralised first permanent molars with post-eruptive breakdown. Eur Arch Paediatr Dent 2013;14:35-9.
51. Cabasse C, Marie-Cousin A, Huet A, et al. Computer-Assisted Intraosseous anaesthesia for molar and incisor hypomineralisation teeth. A preliminary study. Odontostomatol Trop 2015;38:5-9.

52. Fragelli CMB, SOUZA JFde, Jeremias $\mathrm{F}$, et al. Molar incisor hypomineralization $(\mathrm{miH})$ : conservative treatment management to restore affected teeth. Braz Oral Res 2015;29:1-7.

53. Bekes K, Heinzelmann K, Lettner S, et al. Efficacy of desensitizing products containing $8 \%$ arginine and calcium carbonate for hypersensitivity relief in MIH-affected molars: an 8-week clinical study. Clin Oral Investig 2017;21:2311-7.

54. Bakkal M, Abbasoglu Z, Kargul B. The effect of casein phosphopeptide-amorphous calcium phosphate on molarincisor hypomineralisation: a pilot study. Oral Health Prev Dent 2017;15:163-7.

55. de Souza JF, Fragelli CB, Jeremias F, et al. Eighteen-month clinical performance of composite resin restorations with two different adhesive systems for molars affected by molar incisor hypomineralization. Clin Oral Investig 2017;21:1725-33.

56. Fragelli CMB, Souza JFde, Bussaneli DG, et al. Survival of sealants in molars affected by molar-incisor hypomineralization: 18-month follow-up. Braz Oral Res 2017:31:e30.

57. Sönmez H, Saat S. A clinical evaluation of deproteinization and different cavity designs on resin restoration performance in MlH-Affected molars: two-year results. J Clin Pediatr Dent 2017;41:336-42.

58. Dixit U, Joshi A. Efficacy of Intraosseous local anesthesia for restorative procedures in molar incisor hypomineralization-affected teeth in children. Contemp Clin Dent 2018;9(6):272-S77.

59. Folayan MO, Oyedele TA, Oziegbe E. Time expended on managing molar incisor hypomineralization in a pediatric dental clinic in Nigeria. Braz Oral Res 2018;32:e79.

60. Grossi JdeA, Cabral RN, Ribeiro APD, et al. Glass hybrid restorations as an alternative for restoring hypomineralized molars in the art model. BMC Oral Health 2018:18:65.

61. Koleventi A, Sakellari D, Arapostathis KN, et al. Periodontal impact of preformed metal Crowns on permanent molars of children and adolescents: a pilot study. Pediatr Dent 2018;40:117-21.

62. Pasini M, Giuca MR, Scatena M, et al. Molar incisor hypomineralization treatment with casein phosphopeptide and amorphous calcium phosphate in children. Minerva Stomatol 2018;67:20-5.

63. Dhareula A, Goyal A, Gauba K, et al. A clinical and radiographic investigation comparing the efficacy of cast metal and indirect resin onlays in rehabilitation of permanent first molars affected with severe molar incisor hypomineralisation $(\mathrm{miH})$ : a 36-month randomised controlled clinical trial. Eur Arch Paediatr Dent 2019;9.

64. Wong FSL, Winter GB. Effectiveness of microabrasion technique for improvement of dental aesthetics. Br Dent J 2002;193:155-8.

65. Özgül BM, Saat S, Sönmez H, et al. Clinical evaluation of desensitizing treatment for incisor teeth affected by molar-incisor hypomineralization. J Clin Pediatr Dent 2013;38:101-5.

66. Sheoran N, Garg S, Damle SG, et al. Esthetic management of developmental enamel opacities in young permanent maxillary incisors with two microabrasion techniques--a split mouth study. $J$ Esthet Restor Dent 2014;26:345-52. [et al].

67. Restrepo M, Jeremias F, Santos-Pinto L, et al. Effect of fluoride Varnish on enamel remineralization in anterior teeth with molar incisor hypomineralization. J Clin Pediatr Dent 2016;40:207-10.

68. Bhandari R, Thakur S, Singhal P, et al. Concealment effect of resin infiltration on incisor of Grade I molar incisor hypomineralization patients: An in vivo study. J Conserv Dent 2018;21:450-4.

69. Hasmun N, Lawson J, Vettore M, et al. Change in oral health-related quality of life following minimally invasive aesthetic treatment for children with molar incisor Hypomineralisation: a prospective study. Dent J 2018;6. 